\title{
Virtual Home Library System Let every Chinese family having their own libraries
}

\author{
Bin WU ${ }^{1}$, Shu SONG ${ }^{1}$, Jianxiang $\mathbf{C A O}^{2}$, Wen $\mathbf{R U}^{1}$ \\ ${ }^{1}$ Nation Library of China, Beijing 100081, China \\ ${ }^{2}$ Communication University of China, Beijing 100024, China
}

\begin{abstract}
Virtual Home Library (VHL) is an integrated IT system that utilizes virtual reality technology and an IPTV set-top box (STB) to virtually construct a 'library' and the relevant reading environment on televisions in people's home. Unlike the online e-book reading applications, Virtual Home Library can be applied on televisions-the world's most convenient and most efficient communication tool. Providing extended digital library services, it will be a perfect group reading utility for family readers. The system has been investigated by a joint research team formed by the National Library of China and the Communication University of China, collaborating with a Chinese IPTV equipment manufacturer. This paper presents some preliminary investigations of the VHL system performed by the research team.
\end{abstract}

Keywords: virtual home library, IPTV, virtual reality, digital library

\section{虛擬家庭圖書館}

一讓每個中國家庭都擁有自己的“圖書館”

\author{
吳 斌 $^{1}$, 宋 姝 $^{1}$, 曹建香 $^{2}$, 茹 文 $^{1}$ \\ ${ }^{1}$ 中國國家圖書館 北京 $100081 ;{ }^{2}$ 中國傳媒大學 北京 100024
}

\begin{abstract}
摘 要: 虛擬家庭圖書館簡稱 VHL (Virtual Home Library), 是一個採用虛擬現實技術和 IPTV 機頂盒 構建的 IT 集成系統。它可通過電視機在讀者家裏構建一個虛擬的“圖書館”和虛擬的讀書氛圍。不同於 網上在線的電子圖書閱覽器, 虛擬家庭圖書館可以應用在目前世界上最方便、最普及的傳媒工具— 電視上, 並提供拓展的數字圖書館服務, 從而成為可供家庭讀者單獨或群體閱讀的理想設施。國家圖 書館和中國傳媒大學組成的研究團隊, 聯合國內的 IPTV 廠商, 正在對 VHL 系統進行前期調研。本文 就是根據該團隊的前期調研結果對 VHL 系統做一個總體介紹。
\end{abstract}

關鍵詞: 虛擬家庭圖書館, IPTV, 虛擬現實, 數字圖書館 中圖分類號: G250.76

\section{1. 背景介紹}

在一個安靜愉悅的環境下讀書, 大概是人類最普 遍、最㖤意的愛好之一。但是, 在我國的部分地區, 比如偏遠的西部農村地區, 書籍和圖書館仍然是一種 奢侈品。由於書籍的缺乏而引起得知識和教育的不 足, 是導致我國中西部地區、以及城鄉之間經濟發展
不平衡的最主要的原因之一。即使對於發達地區的人 們來說, 有時候閱讀的需求也不能滿足。這可能有兩 方面的原因, 一是在當今社會巨大的工作壓力下, 人 們用來閱讀的時間極為有限; 二是在今天這個資訊爆 炸的時代, 能找到合適的讀物或找到想要的資訊已經 變得越來越困難。

“數字圖書館”以其顯著的優點成為解決上述問題 
的極好方案, 這些優點包括: 大容量的數位資源、隨 時隨地地讀取應用、高效的檢索技術、基於知識聚類 和人工智慧的用戶介面、強大的資料管理功能等等。

一個典型的應用例子就是讀者通過線上的閱讀軟體上 網流覽各種數位圖書。

但用戶要使用數位圖書館的應用必須要具備三個 基本條件:

-互聯網的接入設施

・電腦系統 (包括硬體和軟體)

- 電腦操作技能

雖然我國政府近幾年來已經投入了大量的財力致 力於改善全國範圍內的網路設施, 但不具備電腦操作 的技能 ( 缺乏相關的培訓)、需要購買電腦硬體設備和 商業軟體等等都限制了線上閱讀軟體的應用, 特別是 在農村不發達地區。

本課題研究的“虛擬家庭圖書館”系統 (Virtual Home Library, VHL ), 正是針對上述問題的一個很好 的解決方案。它採用虛擬現實技術和 IPTV ( Internet Protocol Television, 互動式網路電視) 機頂盒, 形成 一個軟硬體集成系統, 並通過電視機在讀者家裏構建 一個虛擬的圖書館和讀書氛圍 (如圖 1, 圖 2 所示)。

不同於網上線上的圖書閱覽器還需要電腦設備和
相應的操作技能, “虛擬家庭圖書館”系統可以應用在 目前世界上最方便、最普及的傳媒工具—電視上。

它的應用只需要兩個條件:

- 互聯網的接入設施

- 普通電視機

簡言之, 只要可以上網, 並有電視機, 通過電視 遙控器, 就能使用“虛擬家庭圖書館”系統進行讀書和 查閱資訊。

而電視機已經在我國普及, 互聯網的普及程度隨 著國家的基礎建設投入也逐年迅速提高, 通過撥號、 xDSL 或 LAN 的方式使用互聯網的家庭越來越多。特 別的, 在首都北京, 上述這兩個條件, 都已滿足。因 而, 在北京使用此項產品, 已經没有問題。

充足的數位資源和全國範圍的網路傳播設施是 “虛擬家庭圖書館”系統應用的兩個基本條件。這兩個 條件目前已由政府的不斷投入而得以保證。首先, 正 在建設中的“國家數位圖書館工程”到 2008 年底將會 提供約 340TB 的數字資源, 並且將保持每年至少 $50 \mathrm{~TB}$ 的增長速度[1]。其次, 2004 年開始的“中國國家文化 資訊共用工程”已逐步建立了一個有效的覆蓋了中國 大陸 31 個行政地區的資料傳輸網路[2]。圖 2 是該資 料傳輸網路的拓撲圖。

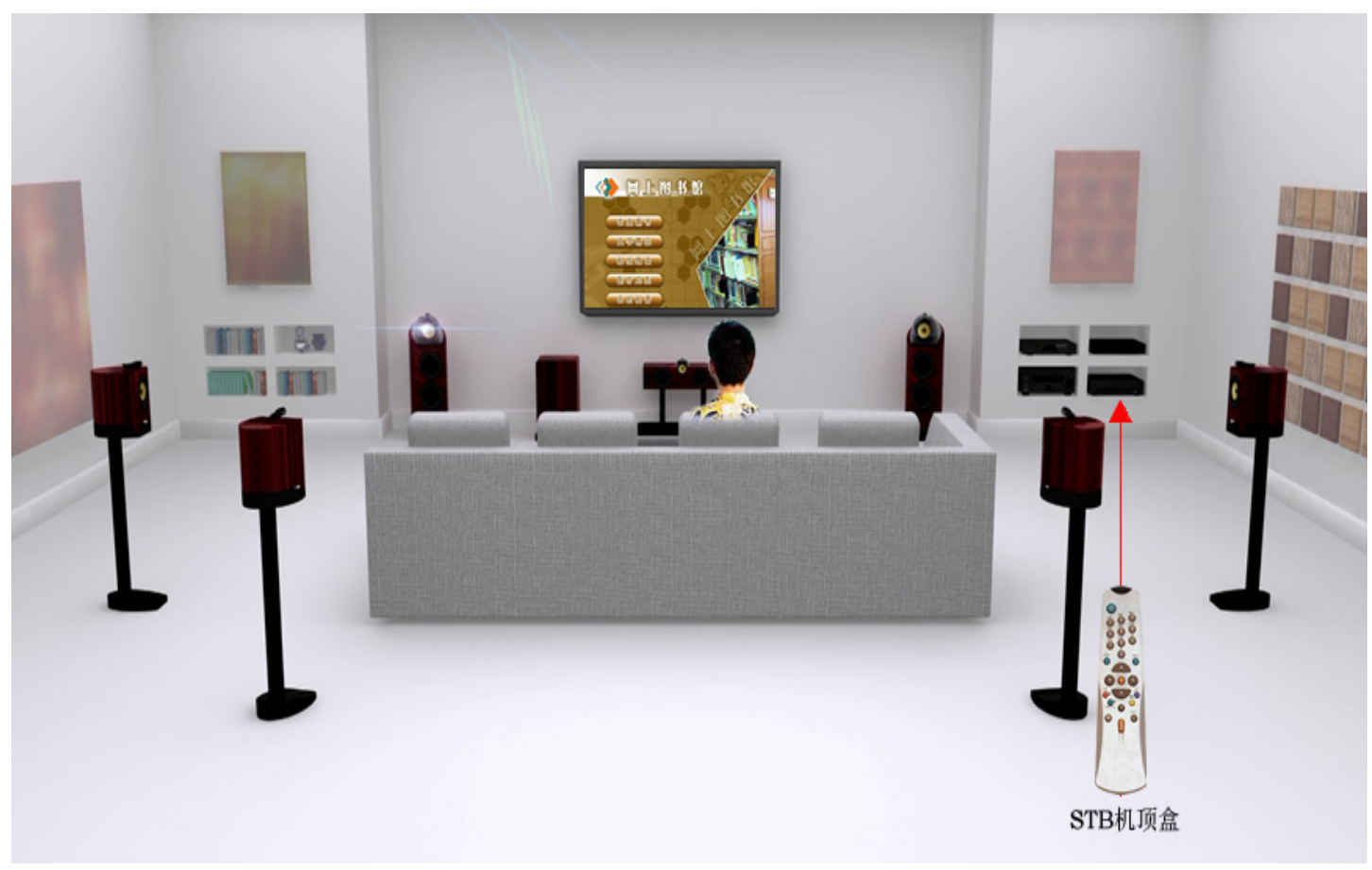

圖 1. VHL 系統的家庭應用

Figure 1. Home implementation of VHL system 


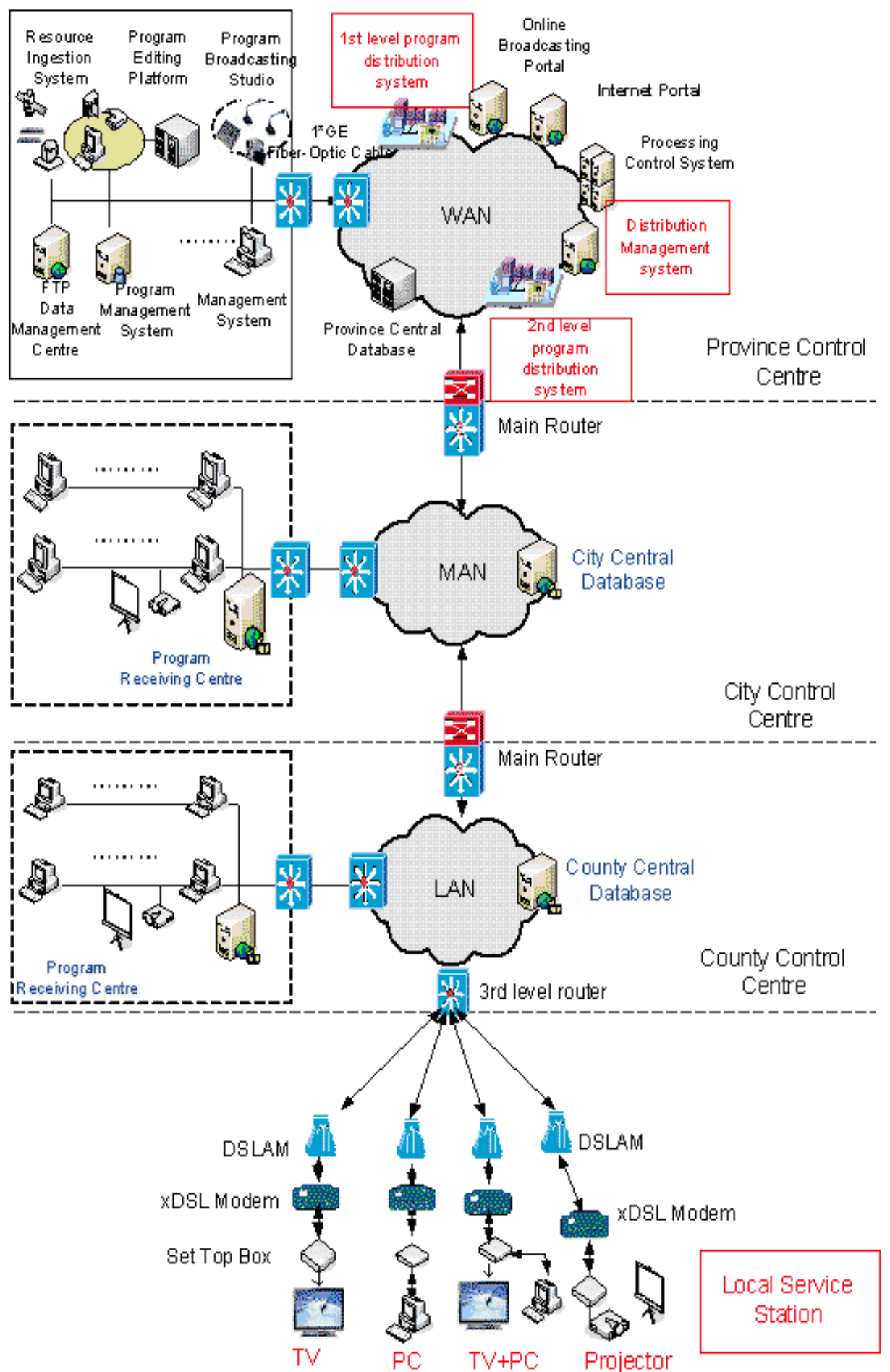

圖 2. 全國範圍的文化資源信息共享工程傳輸網絡拓撲圖

Figure 2. Topology of the nation-wide cultural resources information sharing transmission network

“虛擬家庭圖書館”是國家數位圖書館工程建設中 《虛擬現實》子項目規劃中的一部分 [3], 用以提供數 位圖書館的拓展服務。其前期調研工作是由國家圖書
館主導, 並聯合中國傳媒大學和國內從事 IPTV 機頂 盒研發的生產廠商共同組成的科研團隊進行的。目前 研究工作的目標是要實現一個“虛擬家庭圖書館”的原 
型系統。本文就是對該系統和相閣的研究作一個初步 介紹。

\section{2. 虛擬家庭圖書館 (VHL) 系統和相閣的研 究內容}

一個虛擬家庭圖書館系統由以下兩部分組成:

硬體: 一個具有 CPU 處理器和電視/互聯網介面、 並能對無線控制信號做出反應的 IPTV 機頂盒 STB(Set Top Box)，見圖 3。

-軟體: 可對控制者的操作做出回應的嵌入式虛擬 現實應用軟體。

研究小組將提交一份關於 VHL 系統的完整調研 報告。該報告涉及的軟硬體技術細節主要包括以下幾 個方面:

·用戶需求分析

・硬體相容性/功能操作分析

·人機界面分析

・服務功能分析

·系統集成分析

根據這份研究報告, 可以制定整個系統的設計綱 要, 並設計出原型系統。

目前的研究重點集中在以下兩點:

- “虛擬家庭圖書館”系統中相關軟硬體開發的技 術問題。這些問題包括硬體相容性、嵌入式技術和人 機交互介面等。

- “虛擬家庭圖書館”系統涉及到的數位圖書館服 務相關的技術, 比如: 資料管理、基於知識聚類的檢 索技術等。

\section{3. 虛擬家庭圖書館（VHL）系統的優點}

基於 IPTV 和虛擬現實技術的“虛擬家庭圖書館” 系統將有以下幾個優點:

1) 低投入一一該系統不需要任何電腦硬體, 唯一 一個硬體設備是一個可連接網路和普通電視的 IPTV 機頂盒 ( 如圖 3 所示), 用來切換數位信號轉和類比信 號, 並對用戶的操作做出相應的反應。該機頂盒的費 用不到五百元人民幣。在一些省份的農村家庭和鄉村 圖書館站已經由中央財政、地方政府和“全國文化資訊 共用工程”三家提供了免費的機頂盒[2]。

2) 網路風險低一由於虛擬家庭圖書館系統的 用戶端不具備上傳功能, 並且用來傳輸的大多數數位 資源的帶寬需求相對較低 ( 約 $800 \mathrm{~K}-1 \mathrm{M}$ ), 因而網路

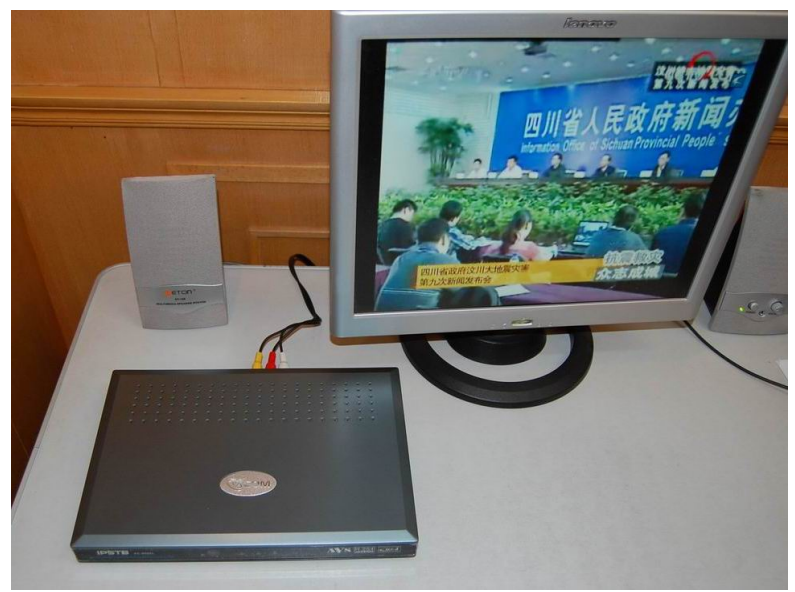

圖 3. VHL 系統使用的機頂盒原物圖

Figure 3. Set Top Box of VHL system

的安全及系統運行的可靠性能夠得到保證。

3）易於維護—DHL 系統所涉及的所有資料的 存儲和傳送都是由管理中心控制的, 系統的升級也是 由中央控制系統發送的進程來完成的。因而在 VHL 系統中無需用戶端做任何維護工作。

4) 不需要電腦操作技能一一由於“虛擬家庭圖書館” 系統是通過電視機來運行的, 所以用戶只需會操作電視 機的遙控器, 不需要任何電腦作業系統的知識和技能。

5) 友好的用戶介面和個性化的功能一一虛擬現 實技術將提供給用戶一個自然的人機交互介面。每個 家庭成員都可在家中定制自己的“書架”內容 (見圖 4 ), 享受個性化的閱讀環境。還有一些功能可以使得 閱讀更加輕鬆, 比如: 通過語音輸出功能讓讀者在放 鬆的時候或者在做其他事情的時候“聽”書。

6）適合群體閱讀一一由於“虛擬家庭圖書館”系 統是通過電視機來實現的, 它自然而然地繼承了電視 機的播放特點和優勢 (相對單個 PC 而言), 比如可供 多人一起進行閱讀、欣賞、娛樂等。

7) 有效快捷的讀取資源——作為數位圖書館的 擴展服務, 虛擬家庭圖書館系統可以擁有數位圖書館 特有的強大服務功能, 比如基於知識聚類的快捷檢索 技術和智慧化的管理功能等。

\section{4. 虛擬家庭圖書館 (VHL ) 系統的創新點}

概括來說, “虛擬家庭圖書館”系統的研發主要有 兩方面的創新：一是數位圖書館在 IPTV 技術上的應 用; 二是虛擬現實的人機交互技術。 


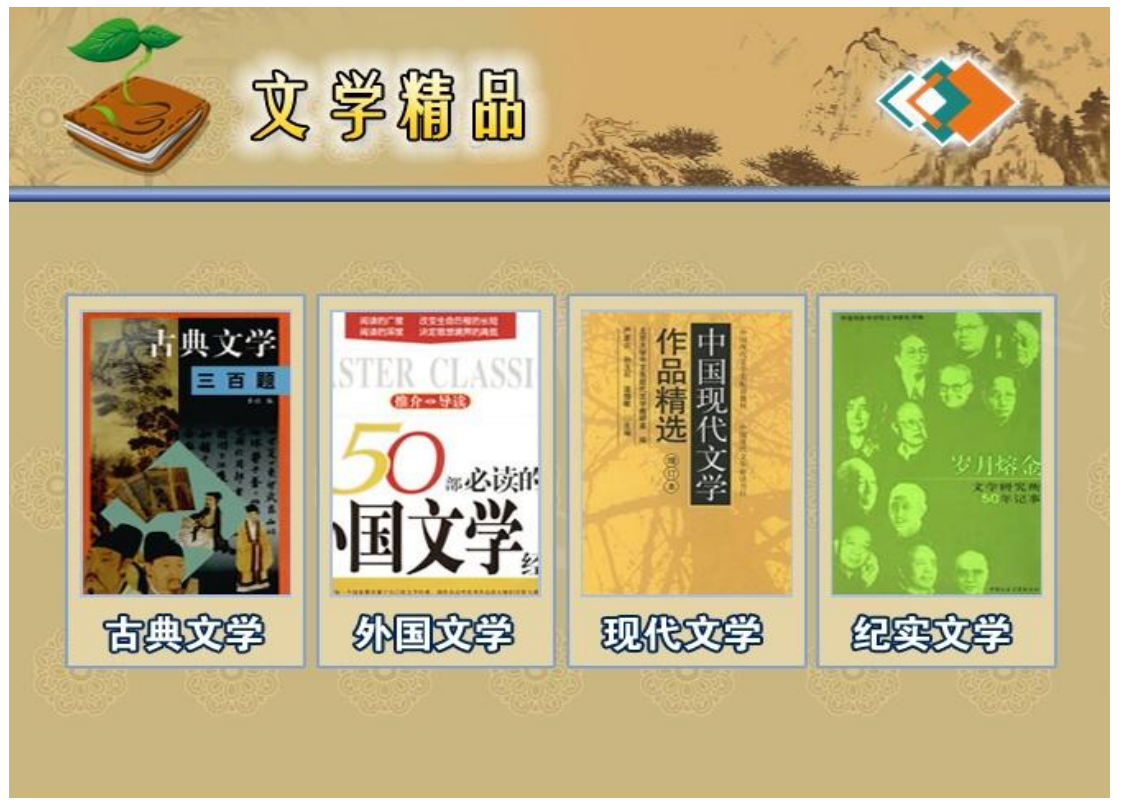

圖 4. 虛擬家庭圖書館系統中的“書架”圖書目錄

Figure 4. An example book selection menu of VHL

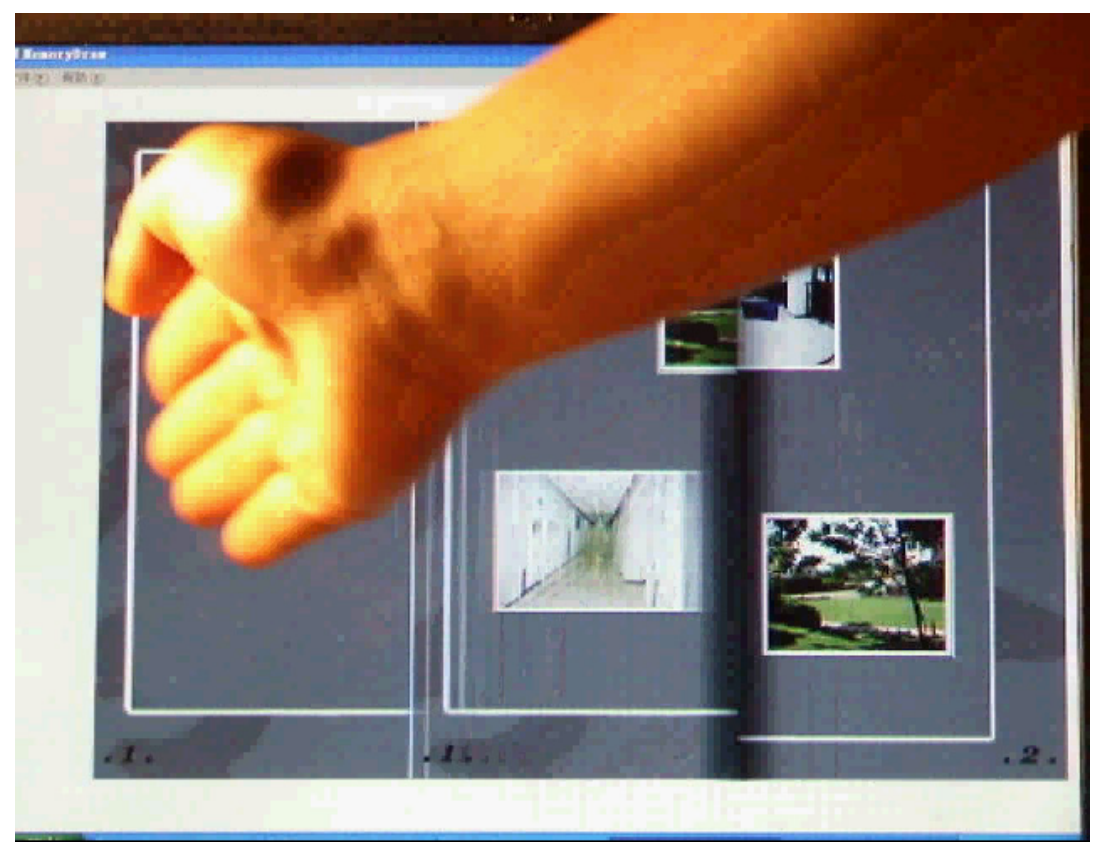

圖 5. 通過外接相機捕捉的手部動作實現翻頁功能

Figure 5. Hand turning pages without touching the screen (detected by a camera)

1) 數位圖書館的 IPTV 應用: “虛擬家庭圖書館” 系統使得數位圖書館的服務可以應用到世界上最廣 泛、最便捷的通訊工具上一一電視上, 而惠及千家萬
戶。這是一個前所未有的創新。它具有操作簡單、易 於維護、價格低廉等優勢, 特別適用于普通中國家庭。 基於虛擬現實技術的人機交互介面: “虛擬家庭圖 
書館”系統中虛擬現實技術的應用, 將會使讀者在電視 上身臨其境地體驗真實“讀書”的效果。家庭中每個成 員都可以在家裏的“虛擬閱讀環境”中享受讀書的樂 趣 讀者可以建立一個屬於自己的虛擬“書架”, “擺放” 從當地或國家數字圖書館借來的各種“圖書”。讀者可 以隨時從該書架上“取”書並“翻開”進行閱讀。同時, 一些新的體驗比如通過電視機的遙控器來實現“翻頁” 功能, 或者更自然地通過外接的攝像頭捕捉讀者的手 部動作來實現閱讀時“翻頁”的功能 (見圖 5 )。此外, 系統的語音輸出功能將會使閱讀的體驗更加輕鬆殹 意, 比如之前描述的“聽”書的功能。

\section{5. “虛擬家庭圖書館”系統 (VHL) 的社會效益}

1) 首先, “虛擬家庭圖書館”系統將有助於數位圖 書館的服務拓展, 可將知識傳播到更遠的地區, 惠及 更多的人群。

目前, 中國是世界上電視機擁有量最多的國家。 截止到 2006 年底, 我國國民家庭電視機擁有量大約為 3.2 億台, 覆蓋了全國大約 $94.8 \%$ 的人口。特別是在農 村地區, 每百戶農村家庭平均擁有 108.6 台電視機, 也就是說每戶農村家庭至少擁有一台電視機。作為國 家重點資訊工程的“村村通網路”專案已在 2007 年 7 月 啟動, 目標是在下一個五年計劃中實現村村通網路。

在“國家數位圖書館工程”、“全國文化資訊共用工 程”、以及中央和地方各級政府的大力支持下，全國範 圍內的資訊基礎設施和充足的數位資源已基本形成。 因而, 從理論上講, 只要擁有電視機和互聯網接入的 家庭都可以成為“虛擬家庭圖書館”的直接用戶。有了 “虛擬家庭圖書館”系統, 我們可以期待, 無論在中國 的城市還是鄉村, 人們都可以方便、經濟、有效地通 過電視機來檢索和閲讀圖書, 使圖書館走進千家萬 戶，使全國人民都可以共用資訊和知識。

2) 其次, “虛擬家庭圖書館”的建設將應用最新的
技術, 比如虛擬現實、人機自然交互介面及基於知識 聚類的資訊檢索技術等。這使得該系統有著巨大的發 展潛力, 比如, 可以融合到新一代的數位電視的發展 以及未來“數位家庭”的發展[4]中。

\section{6. 結 論}

本文對虛擬家庭圖書館系統的前期調研做了一個 總結。該項工作是由一個聯合的研發團隊實施的, 將 作為國家數位圖書館建設中的服務拓展的一部分。目 前的研究目標是開發出一個融 IPTV 技術和虛擬現實 技術於一體的“虛擬家庭圖書館”的原型系統。它能在 讀者家中虛擬地構建 “圖書館”和相關的閱讀環境。由 於可以提供充足的數位資源, “虛擬家庭圖書館”系統 將可以使中國每個家庭都擁有自己的“圖書館”, 足不 出戶地閱讀和流覽各種圖書和資訊。

\section{REFERENCES}

[1] Sun, CJ. and Fu, P., Preliminary Design of the China National Digital Library Project, internal document, National Library of China, June 2005. ( in Chinese ) (孫承鑒, 富平, 孫衛, 等. 國 家數字圖書館初步設計. 中國國家圖書館, 6/2005).

[2] Annual Report 2007, internal document, National Cultural Information Resources Sharing project, Home Page http://www.ndcnc.gov.cn), February 2008.(in Chinese) (全國文 化資訊資源分享工程. 全國文化資訊資源分享工程 2007 年年 報. http://www.ndcnc.gov.cn/).

[3] Wu, B., The Technical Framework of the China National Digital Library, Forum of the $10^{\text {th }}$ Anniversary of the development of Digital Library in China, Shenzhen, China, November 2007.(in Chinese) (吳斌. 國家數位圖書館技術架構. 深圳. 中國數字 圖書館 10 周年論壇, 11/2007).

[4] Introduction of China Digital Home project, media report: http://www.gd-emb.org/detail/id-38689.html, July 2007.(in Chinese)( 中國數 位 元元元家庭工程介紹. http://www.gd-emb.org/detail/id- 38689. html, 07/2007). 